\title{
La competencia federal en el marco del amparo en salud
}

\author{
Federal jurisdiction under the health protection \\ Competência federal para a proteção da saúde
}

Agustín Carignani ${ }^{1}$

\begin{abstract}
RESUMEN. Introducción: el presente trabajo estudia la competencia federal en el marco de las acciones de amparo en salud, también conocidas como bioamparos. Para ello, se toman los conceptos y principios que rigen la competencia federal para luego verlos plasmados en las sentencias judiciales analizadas. Se verán fallos paradigmáticos en cuanto a las interpretaciones judiciales y como estas interpretaciones buscan en definitiva salvaguardar el derecho a la salud y su correlativo derecho a la vida. El objetivo de este trabajo es analizar en los distintos casos jurisprudenciales propuestos, la competencia federal de los amparos en salud. Metodologia: Para ello partiremos de los conceptos y normas que determinan la competencia federal, y desde allí analizar los casos propuestos. Resultados y conclusión: en este orden de ideas, se partirá de la doctrina predominante de competencia federal, sus características y se expondrá una referencia breve de la competencia ratione materiae y ratione personae para establecer el marco teórico del análisis de los casos jurisprudenciales analizados.

Palabras Ilave: Competencia federal. Amparos. Derecho a la salud
\end{abstract}

\begin{abstract}
Introducción: this paper studies the federal jurisdiction under the constitutional motions in health, also known as bioamparos. This paper takes the concepts and principles governing the federal jurisdiction to then see them reflected at the analyzed judicial decisions. Paradigmatic failures regarding judicial interpretations well be studied, and how these judicial decisions seek interpretations ultimately protective the right to health and its correlative taken right to life. Methodology: the aim of this work it is to analyze some jurisprudential cases proposed at the federal jurisdiction. Results and conclusion: from the concepts and rules that determine federal jurisdiction, and from there analyze the proposed cases. In this vein, it will be based on the prevailing doctrine of federal jurisdiction, their characteristics and exposed a brief reference to the subject matter jurisdiction ratione materiae and ratione personae and to establish the theoretical framework of the analysis of jurisprudential cases analyzed.
\end{abstract}

Keywords: Federal jurisdiction. Health protection. Right to health

\footnotetext{
${ }^{1}$ Abogado y Procurador por la Universidad Nacional de Córdoba, Especialista en Derecho Sanitario por la Fundación Oswaldo Cruz Brasil, Maestrando Salud Pública en la Escuela de Salud Pública de la Universidad Nacional de Córdoba, Especializando Derecho Procesal Constitucional por la Universidad Blas Pascal, Diplomado en Instituciones Profundizadas del Derecho del Trabajo por la UNTREF, Diplomado en Riesgo del Trabajo por Club del Derecho, Abogado Asesor por concurso del Ministerio de Salud de la Provincia, Profesor invitado de la Universidad Nacional de Córdoba en la materia Aspectos Jurídicos Procesales e institucionales del Derecho a la Salud.
} 
RESUMO. Introdução: este artigo estuda a jurisdição federal no marco dos mandados de segurança, também conhecidos como bioamparos. Foram estudados os conceitos e princípios que regem a competência federal que logo serão refletidos nas decisões judiciais analizadas. Se houver falhas paradigmáticas sobre as interpretações judiciais e como as interpretações em última análise, protegem finalmente o direito à saúde e seu correlativo direito à vida. $\mathrm{O}$ objeito deste trabalho é analisar alguns casos jurisprudenciais na jurisdição federal. Metodologia: para isso se parte dos conceitos e regras que determinam a jurisdição federal, e analisa os casos propostos. Resultados e conclusão: é baseado na doutrina prevalecente de jurisdição federal e suas características. Faz uma breve referência ao assunto da competência ratione materiae e ratione personae e estabelece o quadro teórico da análise de casos jurisprudenciais.

Palavras-chave: Competência federal. Mandado de Segurança. Direito à saúde.

\section{Introducción}

La determinación de la competencia jurisdiccional es un tema que muchas veces presentan discusiones y esto genera grandes complicaciones en materia procesal lo que repercute en el elemento temporal para llegar a una decisión final y fundada. En especial, en el marco de las acciones de salud en las cuales muchas veces el tiempo no es un aliado de la parte actora y la interposición de una acción en un fuero incompetente puede generar una dilación que en definitiva repercute de manera directa en la necesidad de los justiciables.

En el marco de estas acciones de salud, el proceso judicial de amparo fue aceptado por la Corte Suprema de Justicia de la Nación desde los casos "Siri" y "Kot" previsto y diseñado como un remedio urgente contra todo acto u omisión de autoridad pública o de particulares de carácter estrictamente excepcional, consolidado en la reforma constitucional de 1994 mediante el art. 42 de la CN.

Se deben tener en claro algunas reglas previas a entablar una acción judicial so pena de la declaración de incompetencia. Esto por el amplio espectro de casuística que envuelven las acciones de amparo, particularmente cuando se discuten normas de fondo, como lo son las Leyes de Obras Sociales y del Seguro Nacional del Seguro de Salud, Leyes 23.660 y 23.661 respectivamente; según el demandado sea una empresa de medicina prepaga, una obra social o una administración del seguro de salud provincial; ya sea por el objeto del reclamo, la cobertura de una prestación médica 
asistencial o la pretensión de reembolso de los gastos afrontados por una prestación médica, etc.

Por otro lado, se analizará sucintamente el marco legal de las obras sociales toda vez que de los casos a analizar resultan demandadas o codemandadas y es necesario conocer el marco normativo aplicable a las mismas para el análisis que se propone en el presente trabajo.

\section{La Competencia y la jurisdicción:}

Siguiendo al Prof. Ricardo Haro², y a partir de una concepción genérica del vocablo, identifica a la competencia como "el conjunto de atribuciones que la ley -en sentido material- concede a un órgano estatal”. En una acepción más específica, y remitiéndose en este punto a Rosenberg ${ }^{3}$, se entiende por competencia la "delimitación del círculo de negocios de los distintos tribunales, basada en consideraciones de conveniencia".

Por su parte, Gomez ${ }^{4}$ siguiendo al Dr. Alvarado Velloso, enseña que la "competencia es la extensión funcional del poder jurisdiccional, existiendo entre jurisdicción y competencia una relación cuantitativa y no cualitativa, de género a especie". Define también a la jurisdicción como "el poder - deber de administrar justicia, y la competencia fija los límites dentro de los cuales el juez puede ejercer aquella facultad (deber)".

Para hacer un distingo entre jurisdicción y competencia, podemos decir que mientras la jurisdicción es la potestad o función tomada en forma total y completa, la competencia es la delimitación parcial del ejercicio siempre plenario de la jurisdicción ya sea en razón de la materia, del territorio, de las personas, del grado o del turno. Es decir, la jurisdicción es la potestad de administrar justicia, y la competencia fija los límites dentro de los cuales el juez puede ejercer aquella facultad.

\footnotetext{
${ }^{2}$ HARO, Ricardo; La Competencia Federal, Depalma, Buenos Aires, 1989, p. 13.

${ }^{3}$ ROSENBERG, Leo apud HARO ob. cit. p.13.

${ }^{4}$ ALVARADO VELLOSO apud GOMEZ, Claudio Daniel; Competencia Federal, Mediterránea, Córdoba, 2003, p. 21.
} 
En palabras de Gomez $z^{5}$ "la competencia es la medida de la jurisdicción, porque el juez debe ejercer su jurisdicción en los límites de su competencia”.

En definitiva, "la competencia es el ámbito dentro del cual se puede ejercer una actividad conforme con la ley y, en el caso que nos ocupa, la actividad jurisdiccional”.6.

La competencia federal, está establecida en los arts. 116, 117 y 75 inc. 30 de nuestra Constitución Nacional. Se establece la competencia de la Corte Suprema y los tribunales inferiores de la Nación el conocimiento y decisión de todas las causas que versen sobre puntos regidos por la Constitución, y por las leyes de la Nación (art. 116 CN); el art. 117 establece la competencia de la Corte Suprema por apelación pero reserva su competencia originaria para los casos concernientes a embajadores, ministros y cónsules extranjeros, y en los que alguna provincia sea parte, la ejerce de manera originaria y exclusiva. Finalmente, el art. 75 inc. 30 establece la Competencia del Congreso de ejercer una legislación exclusiva en el territorio de la capital de la Nación y dictar la legislación necesaria para el cumplimiento de los fines específicos de los establecimientos de utilidad nacional en el territorio de la República.

En cuanto a las características de la competencia federal, han sido identificadas de la siguiente manera:

a. Constitucional: Su explicación jurídica está en la misma norma constitucional, como una manifestación de voluntad expresa y directa del poder constituyente, fundacional y primigenio que dio origen al Estado argentino como fruto de la concertación de las provincias en aras del logro de la unidad nacional. Es justamente el art. 116 e la CN la norma cuadro donde están comprendidas las distintas causales de la procedencia de la competencia federal.

b. De Orden Público Constitucional: Ello, ya que la primer jerarquía que adquieren en el ordenamiento jurídico las torna inalterables por la voluntad de los particulares. Este orden público es primigenio y fundacional, y dada su supremacía en la jerarquía normativa, exige su imperatividad, inderogabilidad, irrenunciabilidad e indisponibilidad tanto para los poderes del estado como para los individuos. Sin embargo, encuentra su excepción en los supuestos de prorrogabilidad en la

\footnotetext{
${ }^{5}$ GOMEZ, Claudio Daniel; Competencia Federal, Mediterránea, Córdoba, 2003, p. 21.

${ }^{6}$ FALCON, Enrique M. "La jurisdicción, la competencia y el proyecto de Código Civil y Comercial" Revista de Derecho Procesal 2014-2 - Jurisdicción y Competencia I, Rubinzal Culzoni, Santa Fe, 2014, p. 42.
} 
competencia hacia los tribunales ordinarios en razón de las personas y en situaciones excepcionales.

c. Contenciosa: Es necesario que exista un proceso judicial. Ello toda vez que no procede de oficio y el juez sólo ejerce jurisdicción en los casos contenciosos en que es requerida a instancia de parte. Ello se desprende también del art. 116 de la CN en cuanto prevé que debe existir "causa" o "asunto". Es necesario que existan partes con intereses contrapuestos en discusión y en el marco de un necesario proceso judicial.

d. Limitada y de excepción. La competencia federal sólo está referida y ordenada a la casuística constitucional enumerada de modo concreto en el art. 116 y concordantes de la $\mathrm{CN}$, y siendo la competencia de carácter restrictivo, en caso de duda se deberá estar por principio, a favor de la justicia provincial. Asimismo es de excepción toda vez que la mayoría de las causas se sometan a los tribunales ordinarios o provinciales, relegando a los casos que se someterán a la justicia federal aquellos que se ajusten a las normas que así lo prevén.

e. Privativa y excluyente: Atento la imposibilidad de delegar en los tribunales locales, aquellas materias que, por haber sido delegadas exclusivamente por las provincias al gobierno federal, deben ser juzgadas de manera privativo y excluyente por los tribunales federales, debiendo aquellos, en el caso de radicación de tales causas, apartarse aún de oficio. La Justicia Federal reviste el carácter de custodio de la supremacía del orden jurídico federal. En el caso de la competencia por materia, y al tratarse de materias delegadas por las provincias al gobierno federal, no pueden resignarse a favor de los tribunales provinciales y por tanto deben ser juzgados en forma privativa y excluyente por la justicia federal. Por ello se colige que la competencia por razón de la materia es improrrogable. No sucede lo mismo cuando la competencia resulta por las personas intervinientes, caso en el cual la jurisdicción es concurrente.

f.Inalterable: No toda la doctrina la reconoce como característica de la competencia federal. En definitiva, cuando la competencia es asumida correctamente, la tramitación de una causa por un tribunal federal, las circunstancias sobrevinientes sobre los elementos de la relación jurídica, no pueden alterarla, es decir, trastocarla, cambiarla hacia los tribunales provinciales, así como estos últimos, en similares casos, no pueden derivar su propia competencia hacia la justicia federal. Ello porque la competencia se 
determina de acuerdo con las normas vigentes al momento de iniciarse el proceso, la cual queda fijada e inmutable hasta el final del pleito, aunque sobrevengan circunstancias de hecho que, de haber estado presentes con anterioridad, hubieran podido modificar la situación ${ }^{7}$.

Sobre estos conceptos volveremos al momento de analizar los casos propuestos en el presente trabajo.

\section{Competencia Ratione Materiae:}

La razón de la competencia de la justicia federal ratione materiae se explica cuando entra en juego de modo directo un interés o propósito federal, que deberá ser objetivo, legítimo, real, concreto y con suficiente entidad; se refiere a la naturaleza intrínseca o sustancia federal.

Por lo tanto, si la materia es de esencia federal, necesariamente deberá estar reglada por el derecho federal. El tribunal debe tener muy presente la sustancia de la cuestión jurídica debatida. Se atiende a la naturaleza de la relación litigiosa y a la legislación aplicable al caso. "Esta competencia comprende las causas regidas por la Constitución Nacional, los tratados de derechos humanos y demás tratados internacionales, las leyes federales y todo el conjunto de normas que integran el Derecho federal"8.-

Esto se explica porque la interpretación y aplicación del orden jurídico federal le corresponde preeminentemente al Poder Judicial de la Nación como custodio de la supremacía en la jerarquía normativa del derecho federal sobre el provincial.

La competencia federal en este caso, es improrrogable. Ello porque atento la naturaleza federal de la cuestión y de su pertinente regulación, no resulta coherente que dichas causas deban ser radicadas, conocidas y decididas por tribunales provinciales. La razón se asienta en el carácter de orden público constitucional y por su carácter privativo y excluyente respecto de la justicia provincial.

\footnotetext{
${ }^{7}$ CSJN, Fallos: 327:5261. En similar sentido ALSINA Hugo, La justicia federal, Abeledo Perrot, Buenos Aires, 1931, p. 39 apud HARO Ricardo, Ob. Cit. p. 273.-

8 HARO Ricardo, "La competencia federal de los tribunales del poder judicial de la Nación" Revista de Derecho Procesal 2014-2 - Jurisdicción y Competencia l, Rubinzal Culzoni, Santa Fe, 2014, p. 267.
} 


\section{Competencia federal ratione personae.}

En este supuesto, el elemento que determina la atribución de la competencia, está referido a las personas que intervienen como partes en el proceso. Aquí no interesan ni la materia en discusión ni el lugar donde sucedieron los hechos. Se atiende, en definitiva, a la investidura federal de alguna de las partes en juicio, o al carácter de Estado provincial o a la distinta vecindad o nacionalidad que les corresponde a los litigantes.

Haro ${ }^{9}$ explica que "... ya no interesa el contenido o materia jurídica en debate, sino que se atiende primordialmente a la pertenencia o investidura federal de las personas que actúan como sujetos de la relación litigiosa". El autor nos ejemplifica en este sentido lo previsto en el art. $116 \mathrm{CN}$ al señalar las causas en que sean partes la Nación, las provincias entre sí o con vecinos de otra provincia, entre vecinos de diferentes provincias, entre vecinos con ciudadanos extranjeros.

La competencia en razón de las personas puede ser prorrogada hacia los tribunales locales o provinciales, y se permite que, aún en el caso en el cual la Nación sea parte, o alguna de sus reparticiones autárquicas, pueda declinar la jurisdicción de sus propios tribunales federales en favor de los tribunales provinciales. Esta discrecionalidad -salvo los casos excepcionales de expresa prohibición legal- no tiene otro límite ni condicionamiento que la prudente discrecionalidad que el ejercicio y renuencia que todo derecho implica.

Finalmente, esta prórroga puede ser expresa o tácita según las diversas formas de manifestarse en su concreción ya sea por explícita renuncia o por allanarse a ser demandada en los tribunales provinciales sin articular la declinatoria como excepción de previo y especial pronunciamiento.

En definitiva, la materia y las personas constituyen dos categorías distintas de casos cuyo conocimiento atribuye la Constitución Nacional a la justicia federal y responden a fundamentos distintos.

\footnotetext{
9 HARO Ricardo, "La competencia federal de los tribunales del poder judicial de la Nación" Revista de
} Derecho Procesal 2014-2 - Jurisdicción y Competencia I, Rubinzal Culzoni, Santa Fe, 2014, p. 267.- 


\section{La acción de amparo:}

En el marco del trabajo propuesto no se puede soslayar efectuar una remisión a la acción de amparo en salud, y su encuadre jurídico.

Es así que la acción de amparo ha sido definida como una acción expedita y rápida que procede contra todo acto $u$ omisión de autoridad pública o de particulares que, en forma actual o inminente lesione, restrinja, altere o amenace con ilegitimidad manifiesta las libertades, derechos y garantías reconocidas y acordadas por las constituciones de la Nación y de la Provincia, con excepción de la libertad individual tutelada por el Hábeas Corpus.

El marco normativo aplicable a la acción de amparo está regulado por la Constitución Nacional y la Constitución de la Provincia Córdoba; leyes fundamentales que consagran a la "acción de amparo" como una "acción procesal constitucional" y, en segundo orden, Ley Provincial de Amparo № $4.915^{10}$ sancionada con fecha 9 de enero de 1967, que toma su articulado de la Ley Nacional de amparo № $16.986^{11}$ sancionada el 18 de octubre de 1966, presentando una reglamentación muy similar.

Resulta interesante destacar en este punto que la Ley Provincial ㄲo 10.249 (que viene a su vez a modificar el Código Tributario Provincial ${ }^{12}$ ), desplaza la competencia de los tribunales ordinarios provinciales a los tribunales contenciosos administrativos de la Provincia de Córdoba en todas aquellas materias en las cuales el estado provincial o entes autárquicos resulten demandados. Sin embargo, a pesar de las álgidas discusiones que causó esta modificación, el problema de competencia que plantea no genera discusión en relación a la órbita provincial sobre la cual recaen las acciones de amparo cuando alguna repartición provincial o ente autárquico del estado es demandado en una acción de amparo.

\footnotetext{
${ }^{10}$ Ley Provincial de Amparo, sancionada el 09.01.1967, publicada en el B.O. el 20.01.1967 y entró en vigencia el día $20.01 .1967 . \quad$ Disponible en http://web2.cba.gov.ar/web/leyes.nst/0/2C7A3DB86D80EB2803257F1D0056CFD0?OpenDocument\&Highl ight $=0,4915$ (Consultado el 17/12/2015).-

${ }_{11}$ Ley Nacional de Amparo, sancionada el 18.10.1966, publicada en el B.O. el 20.10.1966 y entró en vigencia el 20.10.1966. Disponible en http://www.infoleg.gob.ar/infoleglnternet/verNorma.do?id=46871 (Consultado el 17/12/2015).

${ }^{12}$ Código tributario Provincial, Ley $n^{\circ} 6.006$ con sus decretos reglamentarios y actualizaciones.-
} 
Como se adelantó en los párrafos que anteceden, las cuestiones de competencia en este tipo de acciones revisten de importancia fundamental al momento de procurar mantener este concepto de medida rápida a la cual se hizo referencia antes.

Como nos explica Toricelli ${ }^{13}$ en esta clase de procesos mucho se ha discutido sobre la conveniencia o no de crear tribunales especializados, sobre la posibilidad de plantear la misma como excepción previa, de admitir o no la declaración de oficio por parte del juez y de distribuir las causas según caigan en la órbita provincial o federal.

Sin embargo, la Corte Suprema de Justicia ha mantenido su postura amplia, entendiendo que "todos los jueces nacionales, dentro del ámbito de sus respectivas jurisdicciones territoriales y sin distinción de fueros, son competentes para conocer en demandas de amparo"14.

En esta misma línea, la Ley Provincial 4915 de esta Provincia de Córdoba, art. 4, establecía la competencia de la acción de amparo al juez con jurisdicción en el lugar que el acto se exteriorice, o tuviere o pudiere tener efecto, cualquiera fuese su competencia por materia y que esté de turno. Sin embargo, no sin mucho disenso, dicha norma viene a ser modificada con la nueva Ley de Presupuesto Provincial n $10.249^{15}$ a la que se hizo una breve referencia anteriormente.

Este art. 4 de la Ley Provincial 4915 resulta coherente con el art. 4 de la Ley Nacional de facto 16.986 que establece el fuero común, al regular que "Será competente para conocer de la acción de amparo el juez de Primera Instancia con jurisdicción en el lugar en que el acto se exteriorice o tuviere o pudiere tener efecto. Se observarán, en lo pertinente, las normas sobre competencia por razón de la materia, salvo que aquéllas engendraran dudas razonables al respecto, en cuyo caso el juez requerido deberá conocer de la acción".

Aún antes de la sanción de la Ley 16.986 se mantuvo la distinción entre el fuero federal y el local ${ }^{16}$. En autos "Asociación Bancaria-Sociedad de Empleados de Banco s/

\footnotetext{
13 TORICELLI, Maximiliano, "La competencia en el Amparo"Revista de Derecho Procesal 2014-2 Jurisdicción y Competencia I, Rubinzal Culzoni, Santa Fe, 2014, p. 374.-

${ }_{14}$ Corte Suprema de Justicia de la Nación, 16-12-59 "Sindicato Obrero del Vestido c/ Comisión Provisoria del Gremio s/Recurso de amparo" Fallos: 245:435. Postura ratificada en: 28-3-60, "Losch, Francisco J. s/ Amparo", Fallos: 246:118; 15-11-65, "Pinedo, Corina y otros", Fallos: 263:296.

${ }^{15}$ Ley Provincial de Presupuesto sancionada 10/12/2014 y publicada en el B.O. 19/12/2014. Disponible en http://www.prensalegiscba.gob.ar/img/notas/adjunto-7265.pdf (Consultada el 17/12/2015).

16 TORICELLI Maximiliano, Ob. Cit. p. 385.
} 
Recurso de Amparo", la CSJN afirmó que "habida cuenta de que el acto que los demandantes impugnan como restrictivo de la libertad ha emanado de una autoridad nacional, resulta evidente que [...] la acción sólo ha podido promoverse ante la justicia federal"17. Esta teoría fue ratificada en distintas oportunidades tales como en el fallo "Sindicato Obrero del Vestido"18 y reafirmada en "Prayones de Lauraglia" al sostener que "la presente acción de amparo tiene por objeto examinar la validez de actos emanados del Gobierno de la Nación, por cuyo motivo corresponde la intervención -ratione materiae- de la justicia federal, en virtud de lo dispuesto en el art. 10 de la Constitución Nacional ${ }^{19}$.

\section{Marco normativo de las obras sociales y empresas de medicina privada:}

Atento a que en las acciones de amparo en salud los demandados resultan ser los distintos estados (entendidos como estado nacional, provincial y municipal) en condición de demandados principales o codemandados, muchas veces resulta que el otro pie de estas acciones son las obras sociales y empresas de medicina privada. Es por esta razón que para completar las partes que resultan de las acciones de amparo, se expondrán algunas consideraciones en relación a las obras sociales y empresas de medicina privada.

Siguiendo con el estudio que nos propone el Dr. Aren ${ }^{20}$ en este punto, decimos que la Ley $23.660^{21}$ de obras sociales determina la tipología y naturaleza de la personalidad de las obras sociales, que son consideradas agentes del seguro de salud y que deben hallarse inscriptas en el registro pertinente. Por su parte, la Ley $23.661^{22}$ en sus primeros artículos contiene las expresiones dogmáticas y didácticas de un discurso de reafirmación del seguro social y en ella se habla de principios consabidos relativos al "seguro social", al "pleno goce del derecho a la salud para todos", de una "concepción

\footnotetext{
${ }^{17}$ CSJN, 26-8-59,Fallos: 244:337 apud TORICELLI, Maximiliano Ob. Cit. p. 385.

${ }^{18}$ CSJN, 16-12-59, Fallos: 245:435.

${ }^{19}$ CSJN, 3-3-70, Fallos: 276:89.

20 AREN, Julio Alberto; Régimen Legal de las Obras Sociales. Agentes del Seguro Nacional de Salud, 2da. Edición, Abeledo Perrot, Buenos Aires, 2012, p. 107.

${ }^{21}$ Ley Nacional sancionada el 29/12/1988 y publicada en el B.O. con fecha 05/01/1989. Disponible en http://infoleg.mecon.gov.ar/infolegInternet/verNorma.do?id=62 (Consultado 17/12/2015)

22 Ley Nacional sancionada el 29/12/1988 y publicada en el B.O. con fecha 05/01/1989. Disponible en http://infoleg.mecon.gov.ar/infolegInternet/anexos/0-4999/63/norma.htm (Consultada el 17/12/2015).-
} 
integradora de salud", todo "en consonancia con los dictados de una democracia social moderna", a "prestaciones de salud igualitarias, integrales y humanizadas", al "mejor nivel de calidad disponible" refiriéndose a las prestaciones de salud, a "un sistema de cobertura universal, de estructura pluralista y participativa" y al propósito de "afianzar los lazos y mecanismos de solidaridad social".

Además de las obras sociales, en nuestro fragmentado sistema de salud encontramos a las obras sociales provinciales -que se encuentran fuera del sistema de las Leyes 23.660 y 23.661, por ejemplo, Córdoba, Corrientes, Jujuy, etc-, otras fuera de dichas instituciones y el PAMI, y el sistema de medicinas privadas que es la tercera columna del sistema de salud en nuestro país.

La distinción entre los tres sistemas no es sólo de carácter subjetivo. El sector público tiene al Estado nacional, provincial y municipal y sus respectivos hospitales públicos, las obras sociales de las leyes 23.660 y 23.661 son personas de derecho privado, financiando servicios médico asistenciales de carácter público no estatal. Los médicos y las empresas de medicina privada corresponden al campo del derecho y a la actividad privada, incluyendo a las grandes mutuales de origen de comunidades extranjeras ${ }^{23}$.

Finalmente, corresponde señalar que las empresas de medicina privada están regidas por la Ley $26.682^{24}$ de Empresas de Medicina Prepaga. Se caracterizan por un contrato de adhesión que suscribe el interesado que acepta al ingresar al plan médico prestacional de la empresa. Al entender de la doctrina es justamente este el nido de conflictos en los contratos prestacionales de estas empresas. La Ley 26.682 en su artículo 1 establece el objeto de la mencionada norma y abarca "los planes de adhesión voluntaria y los planes superadores o complementarios por mayores servicios que comercialicen los Agentes del Seguro de Salud (ASS) contemplados en las Leyes nros. 23.660 y $23.661 "$ ".

En cuanto a la interpretación de los contratos prestacionales celebrados entre las empresas de medicina prepaga y sus afiliados, un criterio restrictivo del que se ha hecho abuso, rechaza todo requerimiento de servicio que no encuadre con precisión en las

${ }^{23}$ Cfr. AREN, Ob. Cit. p. 497.

24 Ley Nacional sancionada el 04/05/2011 y publicada en el B.O. con fecha 16/05/2011. Disponible en http://infoleg.mecon.gov.ar/infolegInternet/anexos/0-4999/84/norma.htm (Consultado el 17/12/2015). 
previsiones contractuales del plan. Un criterio más acorde con los derechos de los usuarios, establece la interpretación más favorable a sus intereses. En tal sentido, el art. 37 de la Ley 24.240 de defensa del consumidor 24.240 dispone que "la interpretación del contrato se hará en el sentido más favorable para el consumidor (...) cuando existan dudas sobre los alcances de su obligación, se estará a la que sea menos gravosa" 25 .

Finalmente resta establecer las prestaciones mínimas a las cuales están obligadas las empresas de medicina prepaga. En este orden de ideas, la doctrina concuerda en que el art. 1 de la Ley 24.754 es contundente en que "las empresas o entidades que presten servicios de medicina prepaga deberán cubrir como mínimo, en sus planes de cobertura médico asistencial, las mismas prestaciones obligatorias dispuestas para las obras sociales, conforme lo establecido por las leyes $23.660,23.661$ y 24.455 y sus respectivas reglamentaciones" 26 .

Sin distraer el tema, y a los fines de referenciar el Programa Médico Obligatorio, consiste en aquellas prestaciones mínimas que deben cubrir las obras sociales y las empresas de medicina prepaga cuyo órgano de aplicación y actualización es la Superintendencia de Servicios de Salud de la nación.

Llegados a este punto, queda expuesto que en definitiva el marco mínimo prestacional queda determinado por el Programa Mínimo Obligatorio y las leyes nacionales 23.660 y 23.661 sin perjuicio de otras normas legales como por ejemplo la de discapacidad (ley nacional no $24901^{27}$ ), que a la postre y como se verá de los casos jurisprudenciales.

\section{El análisis de los casos:}

\section{S., J. c. Sociedad Española de Beneficiencia Hospital Español ${ }^{28}$ :}

El accionante promovió acción de amparo ante la Justicia Nacional en lo Civil en contra de una empresa de medicina prepaga a los fines de que le brinde el $100 \%$ de la

\footnotetext{
${ }^{25}$ En este punto, se considera interesante al menos destacar que La Ley de Defensa del Consumidor es aplicable a las relaciones de consumo en virtud de lo reglado por los arts. 1 y 2 de la mencionada Ley.

${ }^{26}$ AREN, Ob, Cit. p. 504.

27 Ley Nacional de discapacidad sancionada el 05/11/1997 y publicada en el B.O. el día 02/12/1997. Disponible en http://www.infoleg.gov.ar/infoleglnternet/anexos/45000-49999/47677/norma.htm. (Consultada el 17/12/2015).

28 Publicado en La Ley 2003-E, 109, cita online AR/JUR/743/2003.-
} 
cobertura necesaria para afrontar el tratamiento tendiente a mejorar la afección neurológica que afectaba al actor. Expone que la empresa de medicina prepaga se habría desentendido de prestar cobertura al tratamiento médico que dice necesitar a fin de mejorar la afección neurológica, lo cual según el accionante manifiesta violaría sus derechos esenciales a la salud y a la prestación médica. Agrega que se violan disposiciones normativas, entre ellas las determinadas por el Programa Médico Obligatorio, la Ley Nacional 23.661 y la Ley Nacional 24.901 que determina la cobertura integral para las personas con discapacidad.

Surge evidente que lo peticionado por la parte actora excede el cumplimiento de cualquier convención existente entre las partes, sino que lo que se requiere es el cumplimiento de normas nacionales que implementan el Sistema Nacional de Salud, la Prestación Médica Obligatoria.

En su oportunidad, el Señor fiscal de Cámara entendió que "no se vislumbra que la acción pueda incidir en el sistema de salud".

En el plan de medicina prepaga, las prestaciones de salud no estaban cubiertas al $100 \%$.

Sin embargo, la Cámara Nacional de apelaciones entiende que en el marco de la Ley $24.754^{29}$ las empresas o entidades que prestan servicios de medicina prepaga deberán cubrir en sus planes de cobertura médico asistenciales como mínimo las prestaciones obligatorias dispuestas por las obras sociales conforme lo establecido por las leyes 23.660 y 23.661 y reglamentaciones.

En el caso, la Cámara concluye que atento a que se encuentran en juego normas y principios institucionales y constitucionales de prioritaria trascendencia para la estructura del sistema de salud implementado por el Estado nacional, entiende que es de plena aplicación al caso lo establecido por la CSJN que determinó sobre el tema puntual que debe declararse la competencia del fuero civil y comercial federal para entender en la demanda que trata sobre las prestaciones de salud previstas en la ley 23.661.

Comentario: Si bien como se ha planteado, en el caso en que la vulneración de un derecho provenga por parte de un particular, prima facie es la justicia provincial la

\footnotetext{
${ }^{29}$ Ley Nacional de Medicina prepaga. Sancionada con fecha 28/11/1996 y publicada en el B.O. con fecha 23/12/1996. Disponible en http://infoleg.mecon.gov.ar/infolegInternet/verNorma.do?id=41166 (Consultada el 17/12/2015).
} 
competente para resolver el caso puesto a consideración de los tribunales. Máxime toda vez que existía en el caso un contrato celebrado por las partes que así lo establecía. En este sentido, la CSJN ha determinado que "es doctrina reiterada de la Corte que la intervención del fuero federal en las provincias es de excepción, vale decir que se encuentra circunscripta a las causas que expresamente le atribuyen las leyes que fijan su competencia, las cuales son de interpretación restrictiva" ${ }^{30}$. Sin embargo, en el caso, la competencia federal es clara por estar determinada ratione materiae atento a que lo planteado era justamente una prestación prevista en las Prestaciones Médicas Obligatorias y Leyes 23.660, 23.661, 24.754 y Ley de discapacidad 24.901 y en este marco, lo reclamado repercute en el sistema de salud. Como se analizó en los puntos que anteceden, la competencia material de la justicia federal resulta improrrogable, ya que se reserva en el Poder Judicial de la Nación como custodio de la supremacía en la jerarquía normativa del derecho federal sobre el provincial. Torna plenamente operativo la característica de la competencia federal de privativa y excluyente, siendo que la materia que en definitiva se discute, está reservada a la justicia federal y es imposible que sea delegada a la provincia. El mero acuerdo de las partes a someterse a una jurisdicción determinada, no obsta al necesario apartamiento de la justicia provincial a tenor de la entidad de los principios y normas en juego.

\section{Di Franco, Luciano L. c. Swiss Medical S.A. s/ amparo ${ }^{31 .}$}

La parte recurrente interpone su remedio recursivo a la resolución que rechazó una medida cautelar innovativa, sin observar los extremos formales a tales efectos (fundamentación), razón por la cual entiende la Cámara que dicho motivo basta para su rechazado.

Sin embargo, explica que tratándose de un recurso de amparo que versa sobre un tema de salud, y que se ha cuestionado la competencia de los tribunales locales alegando que el tema debió ventilarse ante la competencia federal, siendo ésta de orden

${ }^{30}$ CSJN, 12-3-96, "YPF SA c/ Municipalidad de la Matanza" Fallos: 318:218.

31 Publicado en La Ley Online, cita online: AR/JUR/45169/2012. Disponible en http://www.laleyonline.com.ar/maf/app/documentVM?\&src=laley\&srguid=i0ad6007a00000151b1b8b6524c edf9c7\&docguid=i338088DF2FA6D5D23CB2FCF55629AEDB\&hitguid=i338088DF2FA6D5D23CB2FCF55 629 AEDB\&spos $=1$ \&epos $=1 \&$ td $=1 \&$ ao $=0$. i0ADFAB87AF31 C98881 AF32BF199FB6CB \&searchFrom $=\&$ save $d$ Search=false \&context=10\&crumb-action=append (Consultado el 17/12/2015). 
público, improrrogable, privativa y excluyente y que puede ser declarada en cualquier estado del proceso, la Cámara entiende que corresponde atribuir la competencia ratione materiae al fuero civil y comercial federal resolviendo en definitiva remitir las actuaciones a la Justicia Federal.

Comentario: La conclusión arribada en el presente caso se asemeja en gran medida a la anterior, ello toda vez que la competencia material queda establecida en tanto se encuentra en juego normas y principios institucionales y constitucionales concernientes al sistema de salud implementado por el Estado. Sin embargo, lo que enriquece el caso, es la postura superadora expuesta por el tribunal toda vez que a pesar de haberse interpuesto un recurso sin cumplir con los requisitos formales previstos por la norma legal, particularmente la falta de fundamentación en violación a lo previsto en el art. 365 del Código Procesal Civil, lo que implicaría su denegatoria in limine, y, en su caso, otorgado, implicaría la tacha de mal otorgado por la Cámara revisora. Sin embargo, al haberse planteado la incompetencia de los tribunales provinciales, conforme la urgencia del caso y a los fines de evitar dilaciones, y dado que la competencia federal es de orden público, improrrogable, privativa y excluyente características propias de la competencia federal, pudiendo ser declarada en cualquier estado del proceso, la Cámara resolvió declarar la incompetencia del Tribunal provincial y remitir las actuaciones a la Justicia Federal. Sin perjuicio de lo expuesto, la solución resulta acertada cuando además se toma en consideración que "la incompetencia del juez, no impide decretar medidas cautelares a los fines de evitar perjuicios irreparables a los justificables"32

\section{M., L. c. O.S.P.I.S. (Obra Social Personal de Instalaciones Sanitarias) ${ }^{33}$}

Es competente la justicia federal para entender en una acción de amparo impetrada por una afiliada a fin de que se ordene a la obra social demandada suministrar el tratamiento médico recomendado para el cáncer de mamas por

32 GOMEZ Claudio Daniel, Ob. Cit. p. 626.

33 Publicado en LLNOA (abril), 284 Cita Online AR/JUR/65/2009. Disponible en http://www.laleyonline.com.ar/maf/app/documentVM?\&src=laley\&srguid=i0ad6007a00000151b1baea955b 608cd7\&docguid=i7B2C392402FBA6C4AE4E29C5E3B43E71\&hitguid=i7B2C392402FBA6C4AE4E29C5E 3B43E71\&spos $=1$ \&epos $=1 \& \mathrm{td}=1$ \&ao $=0$. iOADFAB87AF31 C98881AF32BF199FB6CB\&searchFrom $=\&$ save $d$ Search=false \&context=17\&crumb-action=append (Consultado el 17/12/2015). 
encontrarse en riesgo su vida. Atento la asignación de competencia establecida en el art. 38 de la Ley 23.661, al ser accionada una prestadora de salud y encontrándose en juego cuestiones relativas a la prestación de sus servicios, resulta inadmisible la alteración de la competencia ratione materiae por vía de convenio entre partes.

La Cámara trajo a colación un antecedente análogo de la Corte local (Salta) donde atento la naturaleza de orden público que reviste la Ley 23.661 como también el hecho de que se encuentran en juego cuestiones relativas a la prestación de los servicios de salud del agente de salud entre las cuales se encuentra la cobertura obligatoria de medicamentos, resulta inadmisible la alteración de la competencia ratione materiae por vía de convenio entre las partes.

Por tal razón, se resuelve la incompetencia de la justicia local debiéndose remitir las actuaciones al Fuero Federal.

Comentario: En el caso, los justiciables se habían sometido a la competencia de los tribunales provinciales a tenor del convenio de afiliación firmado por la actora con la empresa de medicina prepaga. El juez se declara incompetente de oficio a la luz de las cuestiones que se discuten, aún con el sometimiento de ambas partes a la justicia provincial a tenor del contrato que los vinculaba. Ya desde "Fernandez Bedoya" 34 la Corte dijo que "la declaración de incompetencia en la acción de amparo está expresamente admitida por el artículo 4, segundo párrafo, de la ley 16.986", aceptando la posibilidad de declaración oficiosa de incompetencia en diversos pronunciamientos ${ }^{35}$.

Se hace un análisis pormenorizado de la correspondencia de la competencia en el caso, y el juez resuelve declararse incompetente a la luz de las cuestiones planteadas, entendiendo que en definitiva el caso estaba alcanzado por la inadmisibilidad de la competencia federal "ratione materiae".

${ }^{34}$ CSJN, Fallos: 270:346.

${ }^{35}$ CSJN, Fallos: 276:89; 310:1378, apud TORICELLI, Maximiliano Ob. Cit. p. 391. 


\section{Arcuri, Carmen Alicia c. Galeno S.A. ${ }^{36}$}

Resulta competente el fuero civil y comercial federal para entender en una acción de amparo impetrada por un afiliado contra una empresa de medicina prepaga a fin de obtener la extensión del plazo de cobertura de su internación clínica, pues en este caso cualquier conflicto vinculado con el reparto de competencias judiciales es susceptible de proyectar una demora en la atención del necesitado agravando su situación por motivos de excesivo formalismo.

En el caso, el juez del fuero federal se declaró incompetente por estimar que las circunstancias fácticas que motivaron este proceso guardan conexidad con las cuestiones planteadas en los autos caratulados "Arcuri Carmen Alicia s/ art. 482 del Código Civil" que se tramite en la justicia nacional en lo civil, y, así las cosas, atribuyó su conocimiento al mencionado juzgado. El titular del juzgado nacional no aceptó la competencia que le fue asignada por entender que no existía la vinculación aludida y las devolvió al juez federal que la había remitido anteriormente, quedando configurado de esta manera un conflicto negativo de competencia.

Así la Cámara Nacional Civil y Comercial Federal, dijo tener entendido que el conjunto de normas que integran el sistema nacional de salud debe ser flexible, justamente a los fines de evitar que cuando se ventilen contingencias vinculadas con prestaciones médico asistenciales no se vean divididas en cuanto a su competencia en fueros judiciales distintos a pesar de tener connotaciones de estricta analogía. Se busca evitar la falta de certeza en los litigantes la cual atenta de modo directo contra la seguridad jurídica que es uno de los bienes más preciados del derecho y, por consecuencia necesaria, incertidumbre que dificulta la vigencia real y efectiva de los presupuestos que hacen a la consecución del bien común.

Entendió que un conflicto vinculado con el reparto de competencias judiciales es susceptible de proyectar una demora en la atención del necesitado agravando su situación por motivos de excesivo formalismo.

36 Publicado en DJ 2007-III, 1127. Cita online AR/JUR/6793/2007. Disponible en http://www.laleyonline.com.ar/maf/app/documentVM?\&src=laley\&srguid=i0ad6007a00000151b1bbe5bcaa dce4ac\&docguid=i53914D4535A94F1E85A31096F3E3FE39\&hitguid=i53914D4535A94F1E85A31096F3E 3FE39\&spos $=1 \&$ epos $=1 \& \mathrm{td}=1 \&$ ao $=0$. iOADFAB87AF31 C98881 AF32BF199FB6CB\&searchFrom $=\&$ savedS earch=false \&context=24\&crumb-action=append . (Consultado el 17/12/2015). 
Concluyó que en atención a que las prestadoras privadas de servicios médicos conforman el sistema nacional constitutivo de la dispensa del servicio constitucional y legal de amparo de los derechos a la salud y a la vida, particularmente resguardados por tratados internacionales que tienen rango superior a la legislación común para elevarse al nivel de Carta Magna; declarándose finalmente la competencia del fuero civil y comercial federal.

Comentario: El presente fallo pone de resalto la dificultad en la determinación de la competencia. La Ley Nacional de amparo y sus concordantes normas provinciales preceptúan que “... no podrán articularse cuestiones de competencia..." (art. 16 Ley 16.986), procurando que no se vea afectado el rápido trámite de los amparos. Ello no obsta a que sea el propio juez interviniente quien declare su propia incompetencia con arreglo a las normas del art. 4 de la misma Ley 16.986. En el caso, la Cámara Federal sopesando los intereses en pugna, dio prevalencia a la celeridad y se expidió por la competencia federal.

Como se verá en el próximo caso a analizar, la solución arribada en este caso se opone diametralmente a la que se expondrá en el caso siguiente.

\section{Sarria, Analía Z c. O.S.P.I.D.A. y otro ${ }^{37}$.}

Se interpone la acción de amparo en contra de una obra social y el Ministerio de Salud de la Nación para la entrega o pago de las prótesis necesarias para un menor. La obra social se niega a la prestación con base en una resolución del Ministerio de Salud que limita la cobertura. El Ministerio codemandado interpone la excepción de incompetencia aduciendo que en el caso debe entender la justicia federal. El Juez de primera instancia hace lugar a la incompetencia. La Cámara de Apelaciones revoca esa decisión y divide la jurisdicción manteniendo la competencia provincial para la obra social demandada, asimismo analiza la pretensión de la amparista haciendo lugar a la pretensión.

\footnotetext{
37 Publicado en LLBA2003, 1288. Cita Online AR/JUR/2394/2003. Disponible en http://www.laleyonline.com.ar/maf/app/documentVM?\&src=laley\&srguid=i0ad6007a00000151b1bcee1a81 0d6bd7\&docguid=iAE407A63DEBF11D7896E0001027AD7FD\&hitguid=iAE407A63DEBF11D7896E00010 27AD7FD\&spos $=1$ \&epos $=1 \& \mathrm{td}=1$ \&ao $=0$. iOADFAB87AF31 C98881 AF32BF199FB6CB \& searchFrom $=\&$ save dSearch=false\&context=31\&crumb-action=append . (Consultado el 17/12/2015).
} 
En el caso, la Cámara entiende que la suerte de la causa puede ser distinta para los dos litisconsortes pasivos facultativos, ya que al Estado Nacional se lo demanda en base a su deber de acatar los tratados internacionales en materia de derechos humanos, mientras que a la obra social para que asigne la cobertura que le es propia. En este orden de ideas, entiende que la causa puede escindirse dividiendo la competencia y mantenerse vigente en sede provincial sólo respecto de la obra social codemandada -que no planteó la incompetencia de dicha jurisdicción- y hacer lugar a la incompetencia planteada por el Ministerio de Salud de la Nación codemandado, pretensión que deberá deducirse ante la competencia federal, ya que no hay razón para extender oficiosamente la jurisdicción federal que es de excepción y de interpretación restrictiva.

Comentario: Se entiende que la solución adoptada por la Cámara de Trenque Lauquen no encuentra razón en la solución arribada. Ello toda vez que en definitiva lo que los amparistas buscan es una prestación médica, y en este orden de ideas, no se pueden escindir las prestaciones como pretende la resolución. Pero además, se encontraban en discusión actos emanados de una autoridad federal -Ministerio de Salud de la Nación-. Se pone de manifiesto la naturaleza "federal" de la acción desde que el codemandado reviste ese carácter y además, las normas que regulan los derechos a la salud encuentran sustento en el andamiaje constitucional y los tratados internacionales. Es así que en definitiva, correspondía se avocará la competencia federal a la resolución de la controversia judicial, ya que se entiende que no existía tal posibilidad de escindir las pretensiones y en definitiva el objeto del amparista no era otro que la cobertura médica.

Si bien en el caso, como se expone en la sentencia, no se plantea expresamente la solidaridad pasiva, el Estado Nacional -Ministerio de Salud de la Nación- resulta el garante último del derecho a la salud y a la vida, razón por la cual, se entiende que no se debió apartar de la acción al Estado Nacional y dejando como único demandado a la empresa de medicina prepaga entendiendo que las obligaciones demandadas a cada una de las partes podrían ser escindidas. 


\section{Rosenfeld, Ernesto c. Asociación Mutualista Empleados del Banco de la Provincia y otro ${ }^{38}$.}

Es competente la justicia en lo civil -y no la Justicia en lo Civil y Comercial Federalpara tramitar la demanda promovida contra una mutual si no se encuentra en juego normativa alguna del Programa Médico Obligatorio o del Sistema Nacional de Salud, sino que la discrepancia surge entre el afiliado y la demandada en cuanto al cese de su internación en un instituto de recuperación, a cuyo fin obtuvo una medida cautelar.

La Cámara Nacional de Apelaciones en lo Civil, sala $\mathrm{K}$ entiende que no se encuentra en juego normativa alguna de dichos sistemas la que ni siquiera ha sido invocada por el accionante en el escrito introductorio, sino que la discrepancia surge entre el afiliado y la mutual a la que pertenece en cuanto al cese de su internación en un instituto de recuperación, a cuyo fin obtuvo la medida cautelar ratificada por la Sala.

Agrega que en el caso, en relación a la aplicación del art. 38 de la Ley 23.661 que implementa el sistema nacional de seguro de salud establece la jurisdicción federal para la ANSSAL y los agentes de seguro, se ignora si la demandada reviste este último carácter si la por cuanto no surge de autos que haya efectuado el trámite previsto en el art. 16 del mismo cuerpo legal.

Comentario: En el caso se advierte la competencia local toda vez que lo discutido es sobre el cese de la internación de un afiliado y no se cuestionan las normas 23.660, 23.661 ni ninguna norma legal del Sistema Nacional de Salud. Además, el acto lesivo tampoco deviene de autoridad nacional ni se encuentran en pugna derechos con rango constitucional. En definitiva, entiende a la competencia federal como limitada y de excepción, y toda vez que no se encuentra discutida norma nacional alguna ni emanado de autoridad nacional, no corresponde el fuero federal.

Sin embargo, sería para remarcar que si bien de las constancias de autos puede no surgir que la demandada haya dado cumplimiento al trámite de inscripción previsto en el art. 16 de la ley 23.661, por su actividad no escapa al marco legal previsto por el Sistema Nacional del Seguro de Salud ni de la autoridad de aplicación en los términos

38 Publicado en La Ley Online. Cita online AR/JUR/8969/2005. Disponible en http://www.laleyonline.com.ar/maf/app/documentVM?\&src=laley\&srguid=i0ad6007a00000151b1be09438b 9d1178\&docguid=i3FBE252C2CF246148302167E59826A36\&hitguid=i3FBE252C2CF246148302167E598 $26 \mathrm{~A} 36 \&$ spos $=1$ \&epos $=1 \& \mathrm{td}=1$ \&ao $=0$. iOADFAB87AF31 C98881 AF32BF199FB6CB \&searchFrom $=$ \&savedS earch=false\&context=38\&crumb-action=append (Consultado el 17/12/2015). 
del art. 7 de la misma ley, razón por la cual le cabría la competencia federal ratione personae.

\section{S.I. c. Sociedad Italiana de Beneficiencia en Buenos Aires y otros s/ amparo de salud.}

Un afiliado a una sociedad prestadora de servicios de salud inició acción de amparo contra esta y contra el Ministerio de Salud de la Nación, a fin de obtener el reintegro de las facturas abonadas en concepto de cobertura médico asistencial de su hija menor discapacitada. El Juez Federal en lo Civil y Comercial declinó su competencia. La Cámara revocó dicha resolución.

El Juez Federal civil y comercial se declaró incompetente.

Ante la declaración de incompetencia, la parte actora interpuso recurso de apelación atento a que "no solicitó en la demanda el reintegro de suma alguna abonada por ella, lo que se peticiona es abonarle a la prestataria del servicio la parte impaga de las facturas que la prepaga se niega a pagar aduciendo no corresponderle".

La Cámara entendió que las cuestiones que se debaten no se ciñen a la decisión respecto de meras desavenencias de índole contractual, sino que se exigirá el examen de las normas que estructuran el sistema de salud.

Comentario: La Cámara Federal entiende que lo que se discute en el fondo, son en definitivas normas que estructuran el sistema de salud. Siendo estas leyes las 23.660, 23.661, 24.901, entre otras, corresponde la competencia ratione materiae de la jurisdicción federal. Como ya lo han dicho distintos autores, el problema para determinar la competencia pasa por dilucidar si la solución del pleito depende en concreto, es decir, en forma directa e inmediata del derecho federal invocado, pues si la tutela que se pretende hacer valer en juicio no está directamente fundada en la constitución, tratado o ley especialmente regidos pues la competencia queda reservada para los tribunales locales ${ }^{39}$.

${ }^{39}$ Cfr. TORICELLI Maximiliano, Ob. Cit. p. 389. 


\section{Conclusión:}

La acción de amparo ha sido consagrada como acción expedita y rápida orientada a lograr la mayor celeridad posible en el acceso a la justicia, sin perjuicio del deber de garantizar el principio dispositivo y el derecho de defensa, y así viene siendo usada por los distintos tribunales provinciales, nacionales y federales.

Y más allá de toda discusión sobre el acierto o desacierto de los fallos judiciales traídos a análisis, en todos los casos se ha resaltado el derecho a la salud como un derecho primordial a la vida que debe ampararse a ultranza. $Y$ es en esta tesitura que los distintos jueces que resuelven las causas, en aras de salvaguardar la exigüidad de los plazos o el posible derecho conculcado, se ve en la jurisprudencia las interpretaciones más diversas en relación a un tema tan complejo como la determinación de la competencia judicial.

En definitiva, se reconoce al derecho a la salud y su correlativo derecho a la vida como el derecho fundamental de la persona humana, quedan plasmado a flor de piel en el bloque constitucional resultando EL derecho a proteger desde la constitución nacional y los órganos judiciales. 


\section{Referencias}

\section{Bibliografía Doctrinaria}

1.- Alvarado Velloso apud Gomez, CD; Competencia Federal. Córdoba: Mediterránea, 2003.

2.- Aren, JA; Régimen Legal de las Obras Sociales. Agentes del Seguro Nacional de Salud, 2da. Edición. Buenos Aires: Abeledo Perrot, 2012, p. 107.

3.- Falcon, EM. La jurisdicción, la competencia y el proyecto de Código Civil y Comercial Revista de Derecho Procesal 2014-2 - Jurisdicción y Competencia I. Santa Fé: Rubinzal Culzoni, 2014.

4.- Gomez, CD; Competencia Federal Córdoba: Mediterránea, 2003.

5.- Haro, R. La Competencia Federal. Buenos Aires: Depalma,1989.

6.- Rosenberg, Leo Competencia In Haro La Competencia Federal. Buenos Aires: Depalma, 1989.

7.- Toricelli, M, La competencia en el Amparo. Revista de Derecho Procesal 2014-2 Jurisdicción y Competencia I. Santa Fe: Rubinzal Culzoni, 2014.

\section{Bibliografia Jurisprudencial}

1.- CSJN, Fallos: 327:5261.

2.- CSJN, Fallos: 245:435.

3.- CSJN, Fallos: 263:296.

4.- CSJN, Fallos: 244:337

5.- CSJN, Fallos: 245:435.

6.- CSJN, Fallos: 276:89.

7.- CSJN, Fallos: 270:346.

8.- CSJN, Fallos: $276: 89$ y 310:1378.

\section{Bibliografía Legislativa}

1.- Ley Provincial de Amparo no 4.915, sancionada el 09.01.1967, publicada en el B.O. el 20.01.1967 y entró en vigencia el día 20.01.1967.- 
2.- Ley Provincial no 10.249 sancionada el 10/12/2014 y publicada en el B.O. el $19 / 12 / 2014$.

3.- Ley Nacional de Amparo nํ1․ 16.986, sancionada el 18.10.1966, publicada en el B.O. el 20.10.1966 y entró en vigencia el 20.10.1966.-

4.- Código tributario Provincial, Ley n 6.006 con sus decretos reglamentarios y actualizaciones.

5.- Ley Nacional no 23.660 sancionada el 29/12/1988 y publicada en el B.O. con fecha 05/01/1989.

6.- Ley Nacional $n^{\circ} 23.661$ sancionada el 29/12/1988 y publicada en el B.O. con fecha 05/01/1989.

7.- Ley Nacional nº 24.240 sancionada el 22/09/1993 y publicada en el B.O. con fecha 13/10/1993.

8.- Ley Nacional no 24.754 sancionada el 28/11/1996 y publicada en el B.O. con fecha 23/12/1996.

9.- Ley Nacional no 24.901 sancionada el 05/11/1997 y publicada en el B.O. con fecha 02/12/1997.

10.- Ley Nacional no 26.682 sancionada el 04/05/2011 y publicada en el B.O. con fecha 16/05/2011. 